\title{
Prolonged remission of hypercalcaemia due to parathyroid carcinoma with pamidronate
}

\author{
P.G. Newrick, G.D. Braatvedt, A.J. Webb ${ }^{1}$, E. Sheffield² and R.J.M. Corrall \\ Departments of Medicine, ${ }^{1}$ Surgery and ${ }^{2}$ Histopathology, Bristol Royal Infirmary, Bristol BS2 8HW, UK
}

Summary: Parathyroid carcinoma is rare and the associated hypercalcaemia is often resistant to all treatment. A case is described in which prolonged control of hypercalcaemia has been achieved by infrequent infusions of pamidronate despite continuing hypersecretion of parathyroid hormone.

\section{Introduction}

Carcinoma of the parathyroid glands is a rare tumour accounting for approximately $1 \%$ of all causes of primary hyperparathyroidism. ${ }^{1}$ Most tumours are functional, causing severe hypercalcaemia which is often resistant to all modes of treatment. We report a case which has shown prolonged remissions of hypercalcaemia following single infusions of $15 \mathrm{mg}$ of intravenous pamidronate (aminohydroxypropylidine diphosphonate, APD) despite evidence of continuing hypersecretion of parathyroid hormone from residual tumour.

\section{Case report}

A 47 year old white female developed recurrent nephrolithiasis in 1977 and was found to have nephrocalcinosis and a serum calcium of $3.0 \mathrm{mmol} / 1$ (NR 2.25-2.7). She underwent right lower nephrectomy in 1980 .

In 1981 serum calcium remained elevated at 3.12 $\mathrm{mmol} / \mathrm{l}$ and serum parathyroid hormone (PTH) was $156 \mathrm{pmol} / 1$ (NR <60), suggesting primary hyperparathyroidism. At another hospital a right lower parathyroid tumour measing $1 \times 1.5 \mathrm{~cm}$ was removed and reported as an adenoma. From 1981 to 1984 she remained normocalcaemic. She presented again in January 1988 with symptomatic hypercalcaemia. Serum calcium was $3.5 \mathrm{mmol} / 1$ with PTH elevated at $302 \mathrm{pmol} / \mathrm{l}$.

Re-explorations of neck and mediastinum in May and December 1988 failed to identify parathyroid tissue. During a fourth surgical exploration in May 1989, aided by results of selective angiography and venous sampling for PTH, a nodule was excised along with the right thyroid lobe.

Correspondence: Paul Newrick, M.D., M.R.C.P., Diabetes \& Endocrine Unit, Bristol Royal Infirmary, Bristol BS2 8HW, UK.

Accepted: 10 August 1993
Histology of the nodule was reported as parathyroid carcinoma with evidence of fibrous septae, invasion of contiguous structures, abnormal mitoses and paratracheal lymph node involvement. Review of the 1981 histology indicated that the original parathyroid tumour was in fact a carcinoma.

Following a brief postoperative period of hypocalcaemia she became hypercalcaemic within 3 months. In February 1990, in view of symptoms (serum calcium $2.86 \mathrm{mmol} / \mathrm{l}$ ), she was admitted for a trial of intravenous pamidronate infusion receiving $15 \mathrm{mg}$. Withing 5 days she became normocalcaemic and remained so for 22 months, although serum PTH levels remained persistently elevated (1.4-7.8 $\times$ upper limit of normal). When hypercalcaemia $(2.9 \mathrm{mmol} / \mathrm{l})$ recurred after 22 months she was treated with a second infusion of $15 \mathrm{mg}$ of pamidronate, and normocalcaemia was restored within 3 days and maintained for 9 months. A third recurrence was controlled for 6 months and a fourth infusion for further hypercalcaemia has, to date, controlled the situation for one month. No features to suggest MEN Type I have appeared and throughout she has not been exposed to drugs affecting calcium metabolism. The patient's biochemical course is displayed in Figure 1.

\section{Discussion}

Parathyroid carcinoma is a rare tumour with approximately 100 reported cases. ${ }^{1}$ Multifocal parathyroid malignancy is unusual and accidental parathyroid autotransplantation occurring during neck surgery can result in quasi-malignant histological appearances. Despite this and the notorious difficulties of endocrine histological diagnosis, repeated reviews, and the presence of lymph node involvement, indicate that the diagnosis of parathyroid malignancy is correct. 
Corrected $\mathrm{Ca}++$ (mmol/l)

PTH (multiples of ULN)

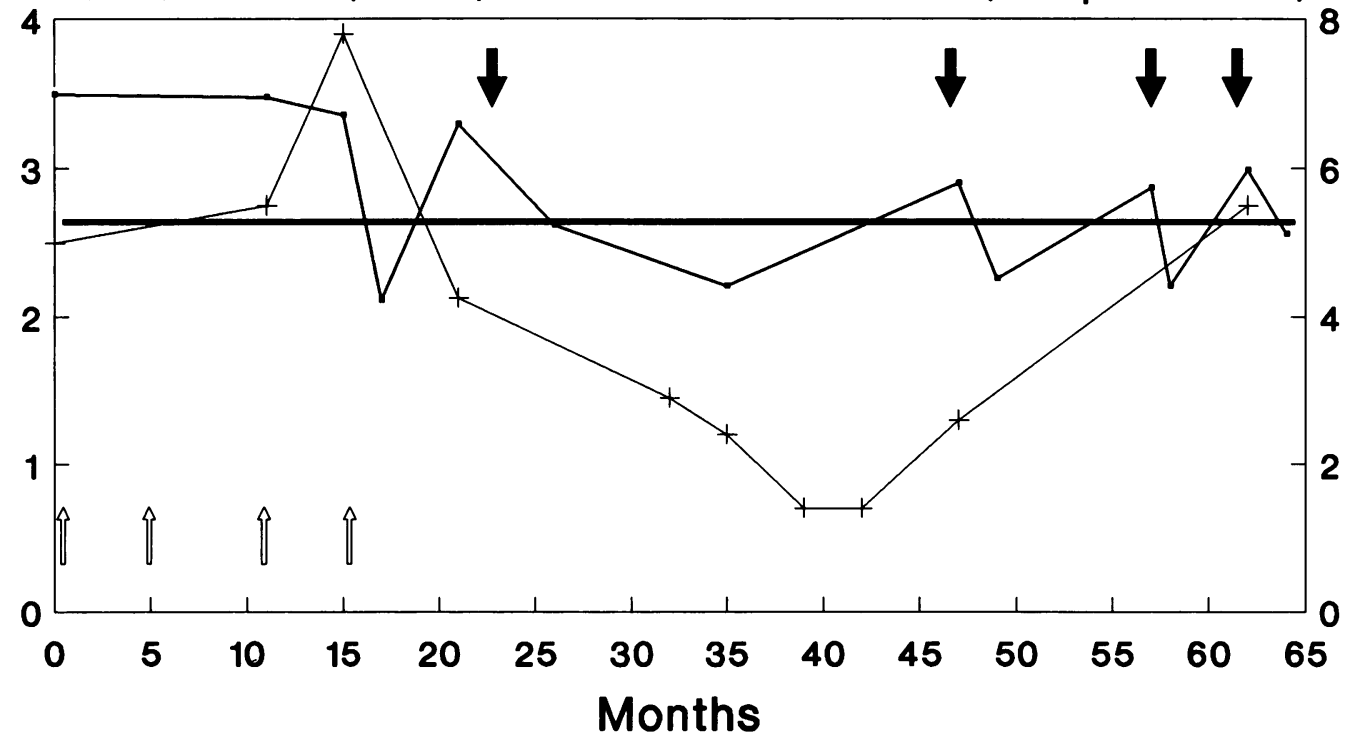

Figure 1 Serial measurements of calcium $\left(\mathrm{Ca}^{++}\right)$and parathyroid hormone (PTH) levels in a patient with parathyroid carcinoma treated with pamidronate (APD). $\square=\mathrm{Ca}^{++} ;+-+=$PTH; $\checkmark=$ ADP infusion; $\hat{\mathrm{V}}=$ surgery; ULN = upper limit of normal.

Bisphosphonates are an established treatment for malignant hypercalcaemia, although early recurrence of hypercalcaemia within weeks is common. The mechanism of their action is via a decrease in bone resorption. Short-term studies with clodronate ${ }^{2}$ and pamidronate ${ }^{3}$ have shown reductions of serum calcium in primary hyperparathyroidism. The results of previous reports of medical treatment for recurrent hypercalcaemia of parathyroid carcinoma, however, are disappointing.

Oestrogens, calcitonin and mithramycin offer only short-term benefit. Intravenous clodronate, $500 \mathrm{mg}$ three times weekly, has been reported as useful in this situation, also with no change in elevated PTH levels. ${ }^{4}$ In one case ${ }^{5}$ serum calcium was lowered but not normalized by oral pamidronate given for 3 months with a suggestion of lowered PTH levels.

The present case is highly unusual in that a single

References

1. Cohn, K., Silverman, M., Corrado, J. \& Sedgewick, C. Parathyroid carcinoma: the LaHey experience. Surgery 1985 , 98: $1095-1100$.

2. Hamdy, N.A.T., Gray, R.E.S., McClosky, E. et al. Clodronate in the medical management of hyperparathyroidism. Bone 1987, 8 (Suppl. 1): 569-577.

3. Schmidli, R.S., Wilson, I., Espiner, E.A., Richards, A.M. \& Donald, R.A. Aminohydroxypropylidine disphosphonate (APD) in mild primary hyperparathyroidism: effect on clinical status. Clin Endocrinol 1990, 32: 293-300. dose of intravenous pamidronate produced 22 months of normocalcaemia. Second and third doses subsequently achieved control for 9 and 6 months, respectively. The duration of the response is surprising. Parathyroid infarction is a possibility but the evidence of continued tumour activity as judged by elevated PTH levels suggests prolonged uncoupling of the bone resorption-formation cycle following pamidronate. Unfortunately we do not have urinary calcium studies to demonstrate whether the normocalcaemic state is truly consecutive to inhibition of bone resorption rather than renal tubular calcium leak, although this latter seems very unlikely given the recurrent nature of the hypercalcaemia in the face of relatively stable renal function.

Such control of hypercalcaemia in parathyroid carcinoma with a bisphosphonate may be very rare but is worthy of consideration in all such patients and might even prolong survival.

4. Jungst, D. Disodium clodronate effective in management of severe hypercalcaemia caused by parathyroid carcinoma. Lancet 1984, 2: 1043 (letter).

5. Mann, K. Oral biphosphonate therapy in metastatic parathyroid carcinoma. Lancet 1985, i: 101-102. 